\title{
Comparison of Physicochemical Characteristics of Microcrystalline Cellulose from Four Abundant Kenyan Biomasses
}

\author{
Murigi $\mathrm{M} \mathrm{K}^{1}$, Madivoli E S ${ }^{1}$, Mathenyu $\mathrm{M} \mathrm{M}^{1}$, Kareru $\mathrm{P} \mathrm{G}^{1^{*}}$, Gachanja A $\mathrm{N}^{1}$, \\ Njenga $\mathrm{P} \mathrm{K}^{2}$, Nowsheen $\mathrm{G}^{3}$, Githira $\mathrm{P} \mathrm{N}^{1}$ and Mercy Githua ${ }^{1}$ \\ ${ }^{l}$ Chemistry Department, College of Pure and Applied Sciences, Jomo Kenyatta University of Agriculture and \\ Technology, Kenya \\ ${ }^{2}$ Department of Botany, College of Pure and Applied Sciences, Jomo Kenyatta University of Agriculture and \\ Technology, Kenya \\ ${ }^{3}$ Centre for Biomedical and Biomaterials Research, University of Mauritius, Mauritius
}

\begin{abstract}
Microcrystalline cellulose (MCC) powders extracted from banana stem, rice straws, water hyacinth and papyrus reeds were investigated for their physicochemical properties. Preparation of the MCC was carried out using the alkali hydrolysis process followed by further treatment using peracetic acid. The lignocellulosic biomasses were first treated with aqueous sodium hydroxide to remove lignin and hemicelluloses followed by further treatment with a solution of peracetic acid at $80^{\circ} \mathrm{C}$ for 2 hours to remove residual lignin and hemicellulose. The obtained cellulose was then bleached with $20 \%$ hydrogen peroxide to whiten the products. Further treatment of cellulose with $2.5 \mathrm{~N}$ hydrochloric acid converted it into microcrystalline cellulose. MCC from rice straws was modified with citric acid and its characteristics compared to unmodified cellulose. Physical characteristics of the microcrystalline cellulose were determined by obtaining the bulk densities, tapped densities, Carr's index, Hausner's ratio and wettability. Further characterization was done using FTIR spectrophotometer, Differential Scanning Calorimeter, Thermal Gravimetric Analysis and Scanning Electron Microscope (SEM). Apart from the SEM micrographs, MCC parameters of the four biomasses determined were not very different.
\end{abstract}

Keywords: Alkali hydrolysis, biomasses, Carr's index, microcrystalline cellulose, Spectrophotometer

\section{Introduction}

Cellulose is one of the most abundant and biodegradable polymers that has a promising future in the production of various materials used for variety of applications. Cellulose is receiving much attention because it is a renewable resource, biodegradable and available en-masse. For instance, agricultural refuse is primarily composed of cellulose, hemicelluloses and lignin. Other cellulosic sources include cereal and vegetable wastes such as straw, bagasse, stover, maize cobs, cotton and groundnut husks and fibrous remnants of forages such as grass, among others (Azubuike $e t a l, 2012$ ). On a global scale the quantity of cellulosic wastes available varies with the predominant agricultural and industrial crop produced in a given society. Although lignocellulosic wastes have found significant application as sources of heat and electric energy, it is believed that considerable value addition may be achieved by using these wastes for the production of cellulose derivatives which have significant economic value. Chemical modification is possible due to an abundance of hydroxyl groups on the surface of the cellulose backbone (Fig. 1).

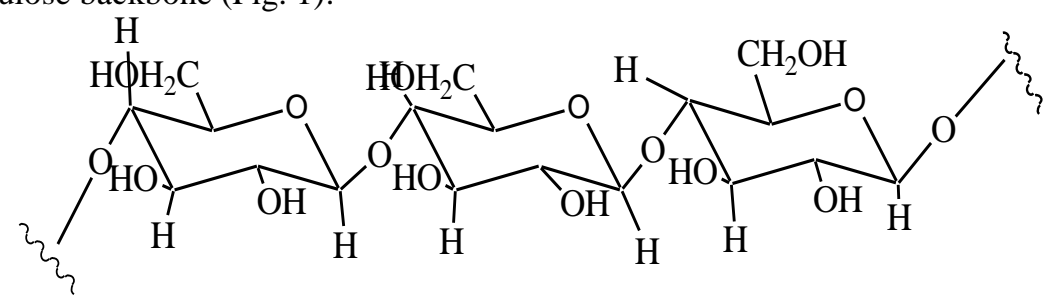

Figure 1. Structure of cellulose

Modified cellulose derivatives have found applications in water purification, reinforcement (Mohamed et al, 2005) and biosensors (Hari et al, 2005). More recently modified cellulose has been used in a variety of applications such as in bio-applications, as antimicrobials, green catalysts and in controlled delivery systems (Edmond et al, 2012), among others

This study reports the physical properties of microcrystalline cellulose (MCC) produced from rice straw, papyrus reed, banana stem and water hyacinth biomasses. In addition, microcrystalline cellulose from rice 
straws was modified with citric acid and its physicochemical characteristics compared to MCC from the former biomasses.

\section{Collection of biomasses}

\section{Materials And Methods}

Water hyacinth and papyrus reeds were collected from Kiambu County of Kenya, while banana stems and rice straws were supplied courtesy of J.K.U.A.T farm. The samples were air dried, washed to remove particulates and then oven dried overnight at $105^{\circ} \mathrm{C}$. Before isolation of cellulose, dried samples were ground to pass through a mesh size of $144 \mathrm{~mm}$.

\section{Isolation of Cellulose from biomass}

Dried and ground biomass was mixed with $10 \%$ aqueous $\mathrm{NaOH}$ solution in a ratio of 1:10 and the mixture stirred for 3 hours at $100{ }^{\circ} \mathrm{C}$, followed by filtration and then washing with $10 \%$ ethanol and distilled water. The hemicellulose-free biomass cake was then dried in an oven at $100^{\circ} \mathrm{C}$ to constant weight followed by treatment with peracetic acid in a ratio of $1: 5$ of the initial weight at $80^{\circ} \mathrm{C}$ for 2 hours. The residue was filtered and washed with distilled water repeatedly and oven-dried at $105^{\circ} \mathrm{C}$ to constant weight. The resulting alphacellulose was further treated with $20 \%$ hydrogen peroxide in a ratio of $1: 5$ at $75^{\circ} \mathrm{C}$ repeatedly until the material became milky white.

\section{Preparation of microcrystalline cellulose $(\mathrm{MCC})$}

Microcrystalline cellulose was prepared according to a method described by Janardhnan et al but with some modifications. $50 \mathrm{~g}$ of oven dried cellulose pulp was added to $100 \mathrm{ml}$ of $2.5 \mathrm{~N}$ hydrochloric acid preheated at $85^{\circ} \mathrm{C}$ and heated for 15 minutes at $85^{\circ} \mathrm{C}$. The microcrystalline cellulose was then washed with distilled water and percentage recovery calculated.

\section{Modification of MCC from rice straws with citric acid}

The chemical modification of obtained pulp was made according to a similar method previously described by Thanh et al with little modification on reaction parameters. $10 \mathrm{~g}$ of microcrystalline cellulose was mixed with $30 \mathrm{~g}$ of citric acid in $8 \mathrm{~mL}$ of water. After being stirred for $30 \mathrm{~min}$ at $20^{\circ} \mathrm{C}$, the acid straw slurries was placed in a porcelain tray and dried at $50^{\circ} \mathrm{C}$ in a forced air oven. After $24 \mathrm{~h}$, the thermochemical reaction between acid and straw was preceded by heating the reaction vessel in a water bath set at $120^{\circ} \mathrm{C}$ for $12 \mathrm{~h}$. After cooling, the reacted product was washed with $200 \mathrm{~mL}$ distilled warm water per gram of product to remove any excess of citric acid. This was confirmed when no turbidity from lead (II) citrate was observed when the washed straw was suspended in $10 \mathrm{~mL}$ of water to which $10 \mathrm{~mL}$ of $0.1 \mathrm{M}$ lead (II) nitrate was added. The citric acid modified cellulose (citric acid-WC) was then dried at $50^{\circ} \mathrm{C}$ to constant weight.

\section{Determination of Bulk and Tapped density}

Each of the $10 \mathrm{~g}$ of MCC material was poured at an angle of $45^{\circ}$ into a $50 \mathrm{ml}$ glass measuring cylinder. Before determining the tapped density the bulk density was first determined by measuring $\mathrm{V}_{0}$. The tapped density was then determined by measuring the final volume, $\mathrm{V}_{1}$, after 20 taps. The tapped and bulk densities were determined as reported by a method described by Azubuike et al, 2012.

\section{Determination of Carr's index and Hausner ratio}

Carr's index and Hausner ratio for cellulose were calculated from bulk and tapped densities using a method described by Azubuike et al.

\section{Determination of Wettability of MCC specimens}

Five grams $(5 \mathrm{gm})$ of each MCC sample was placed in a beaker and dried in an oven at $105^{\circ} \mathrm{C}$ to constant weight. Using a dropper, distilled water was then added to each sample until wet. The final weight of the beaker was determined and the amount of water absorbed calculated as a percentage using the procedure described by Azubuike et al.

\section{FT-IR Spectra of MCC and citric acid modified MCC}

Infrared spectra were recorded using a Shimadzu 8400 FT-IR spectrophotometer. $1 \mathrm{mg}$ of powdered samples were finely ground with $250 \mathrm{mg}$ of $\mathrm{KBr}$ and pressed into a pellet using a Shimadzu hand-press. The spectra were recorded between $4000-400 \mathrm{~cm}^{-1}$ by placing each pellet in the beam of the FT-IR spectrophotometer. 


\section{TGA Experimental Protocols}

Netzsch TG 209 F3 Tarsus ${ }^{\circledR}$ analyzer (Chennai, India) was used to measure and record the sample mass change with temperature over the course of the pyrolysis reaction. Thermogravimetric curves were obtained at a heating rate of $10{ }^{\circ} \mathrm{C} / \mathrm{min}$ between $25^{\circ} \mathrm{C}$ and $1000{ }^{\circ} \mathrm{C}$. Nitrogen was used as an inert purge gas to displace air in the pyrolysis zone, thus avoiding unwanted oxidation of the sample. The sample mass used was approximately $10 \mathrm{mg}$.

\section{DSC Experimental Protocols}

Differential Scanning Calorimetry (DSC) analysis was carried out using a Netzsch DSC 200 F3 Maia® thermal analyzer (Chennai, India). All blend samples $\left(10 \mathrm{mg}\right.$ ) were heated from 30 to $400{ }^{\circ} \mathrm{C}$, cooled to $20{ }^{\circ} \mathrm{C}$ and reheated to $400{ }^{\circ} \mathrm{C}$ at $10^{\circ} \mathrm{C} / \mathrm{min}$.

\section{SEM experimental protocols}

Morphological analysis of MCC and citric acid modified MCC was performed using Zeiss ultra plus Scanning electron microscope operated at accelerating voltage of $20 \mathrm{kV}$ at an aperture size of $30 \mu \mathrm{m}$.

\section{Yield of MCC from biomass and physical parameters}

Table 1 summarizes the physical parameters that were determined in five replicate samples for MCC obtained from each biomass. Water hyacinth gave the highest MCC yield of $23.632 \pm 3.87 \%$ while banana stem gave the lowest yield of $18.353 \pm 1.01 \%$. MCC prepared from water hyacinth had the highest tapped density of $0.3657 \pm 0.010$ and bulk density of $0.2829 \pm 0.0039 \mathrm{gm} / \mathrm{cm}^{3}$ respectively and thus had better compressibility and compatibility properties. The bulk and tapped densities followed the order: water hyacinth $>$ banana stem > rice straws > papyrus reeds respectively. The bulk and the tapped densities are a measure of how well powdered samples can be compacted and compressed in a confined space. In general, the higher the bulk and tapped densities, the better the potential for a material to flow and rearrange under compression ${ }^{3}$. Choice of MCC for various applications is dependent on the yield and physical properties obtained from the biomasses.

From the results obtained (Table 1), it was evident that of the four microcrystalline samples prepared, MCC from banana stem had the best flow ability while that from papyrus reeds had poor flow ability. Flow ability of MCC produced was of the order: banana stem > water hyacinth > rice straws $>$ papyrus reeds. The Hausner ratio and Carr's index are both measures of the flow properties of powders (Azubuike et al, 2012). A Hausner ratio of $<1.25$ indicates a powder that is free flowing where as $>1.25$ indicates poor flow ability. The flow ability is important in pharmaceutical applications.

\begin{tabular}{|c|c|c|c|c|}
\hline Parameter & Water hyacinth & Papyrus reeds & Rice straws & Banana stem \\
\hline Yield \% (w/w) & $23.39 \pm 1.61$ & $23.63 \pm 3.87$ & $19.62 \pm 1.01$ & $18.35 \pm 0.10$ \\
\hline Bulk density $\left(\mathrm{g} \mathrm{cm}^{-3}\right)$ & $0.283 \pm 0.004$ & $0.121 \pm 0.024$ & $0.219 \pm 0.009$ & $0.278 \pm 0.011$ \\
\hline Tapped density $\left(\mathrm{g} \mathrm{cm}^{-3}\right)$ & $0.366 \pm 0.010$ & $0.276 \pm 0.050$ & $0.307 \pm 0.011$ & $0.335 \pm 0.008$ \\
\hline Carr's index & $22.56 \pm 2.29$ & $56.01 \pm 3.63$ & $28.93 \pm 1.29$ & $16.63 \pm 1.31$ \\
\hline Hausner's ratio & $1.29 \pm 0.04$ & $2.28 \pm 0.17$ & $1.41 \pm 0.024$ & $1.19 \pm 0.02$ \\
\hline Wettability & $80.93 \pm 1.12$ & $83.79 \pm 1.77$ & $81.34 \pm 0.26$ & $82.01 \pm 1.28$ \\
\hline
\end{tabular}

\section{FT-IR spectra of MCC samples}

FT-IR spectra (Figure $1-5$ ) obtained in this study revealed the presence of functional groups that are characteristic of MCC. The broad absorption band around $3329-3334 \mathrm{~cm}^{-1}$ was attributed to stretching vibrations of hydroxyl groups. The $\mathrm{OH}$ groups may be attributed to adsorbed water, aliphatic primary and secondary alcohols found in cellulose, hemicelluloses and carboxylic acids in the extractives. The shoulder near the $\mathrm{OH}$ stretching vibrations around $2892-2898 \mathrm{~cm}^{-1}$ was attributed to $\mathrm{CH}$ stretching vibrations and corresponded to the aliphatic moieties in polysaccharides. The bands in the region around $1428-1315 \mathrm{~cm}^{-1}$ were assigned to $\mathrm{CH}$ in plane deformation of $\mathrm{CH}_{2}$ groups. The absorption band observed around $898 \mathrm{~cm}^{-1}$ corresponded to $\beta-1,4$ glycosidic linkages while the band around $1053 \mathrm{~cm}^{-1}$ corresponded to ring vibrations and $\mathrm{C}-\mathrm{O}-\mathrm{C}$ links. Tensile vibrations neighboring hydrogen atoms are depicted by a vibrational band around 1650 $\mathrm{cm}^{-1}$ while the band around $2893 \mathrm{~cm}^{-1}$ corresponds to $\mathrm{C}-\mathrm{H}$ asymmetric and symmetric tensile vibrations ${ }^{3}$. The absorbance around 1428,1368, 1315, 1261.4, 1054 and $898 \mathrm{~cm}^{-1}$ are typical of pure cellulose (Granstrom, 2009). Infrared spectra of citric acid modified MCC did not differ from the unmodified cellulose samples. 


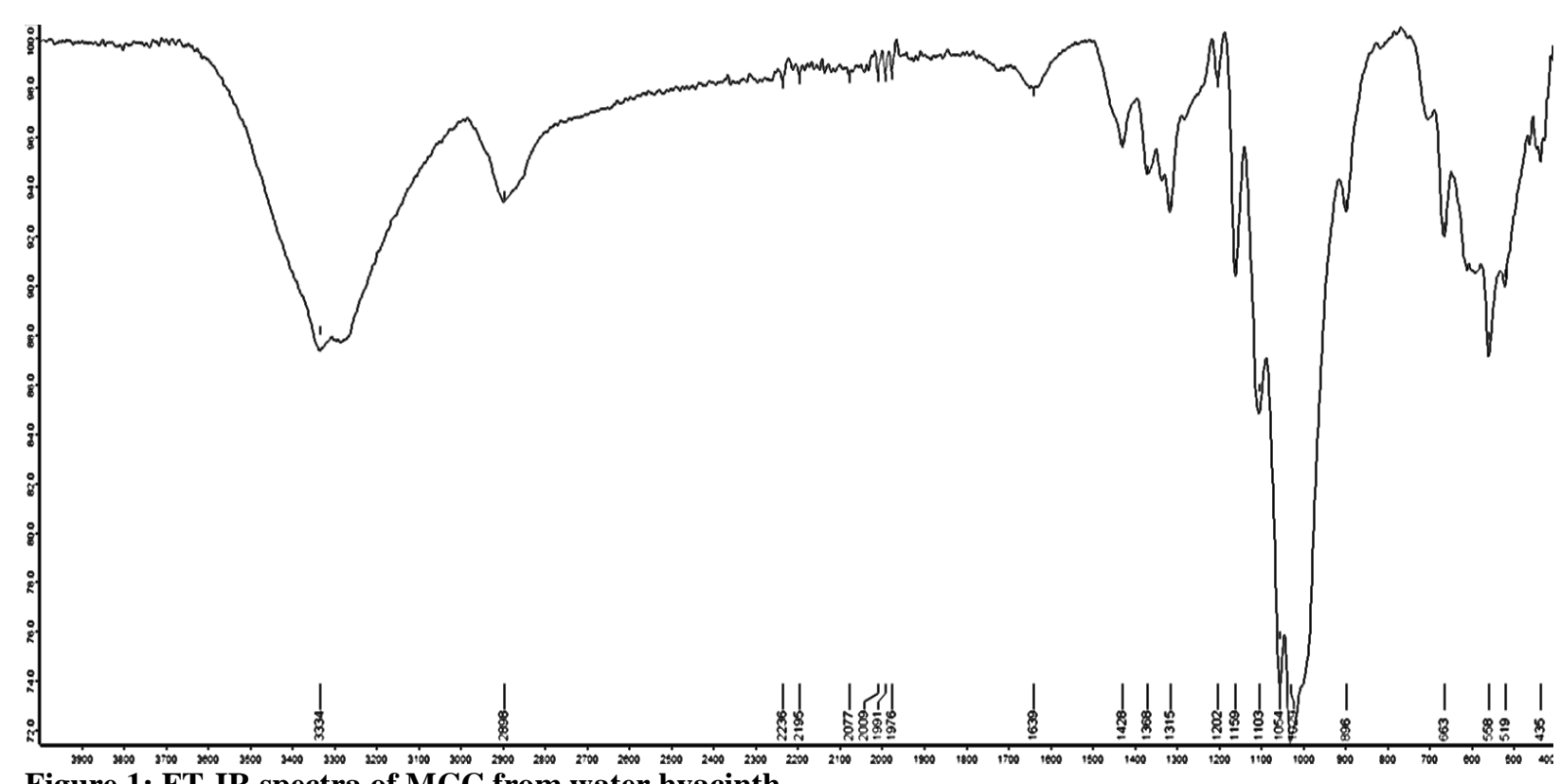

Figure 1: FT-IR spectra of MCC from water hyacinth

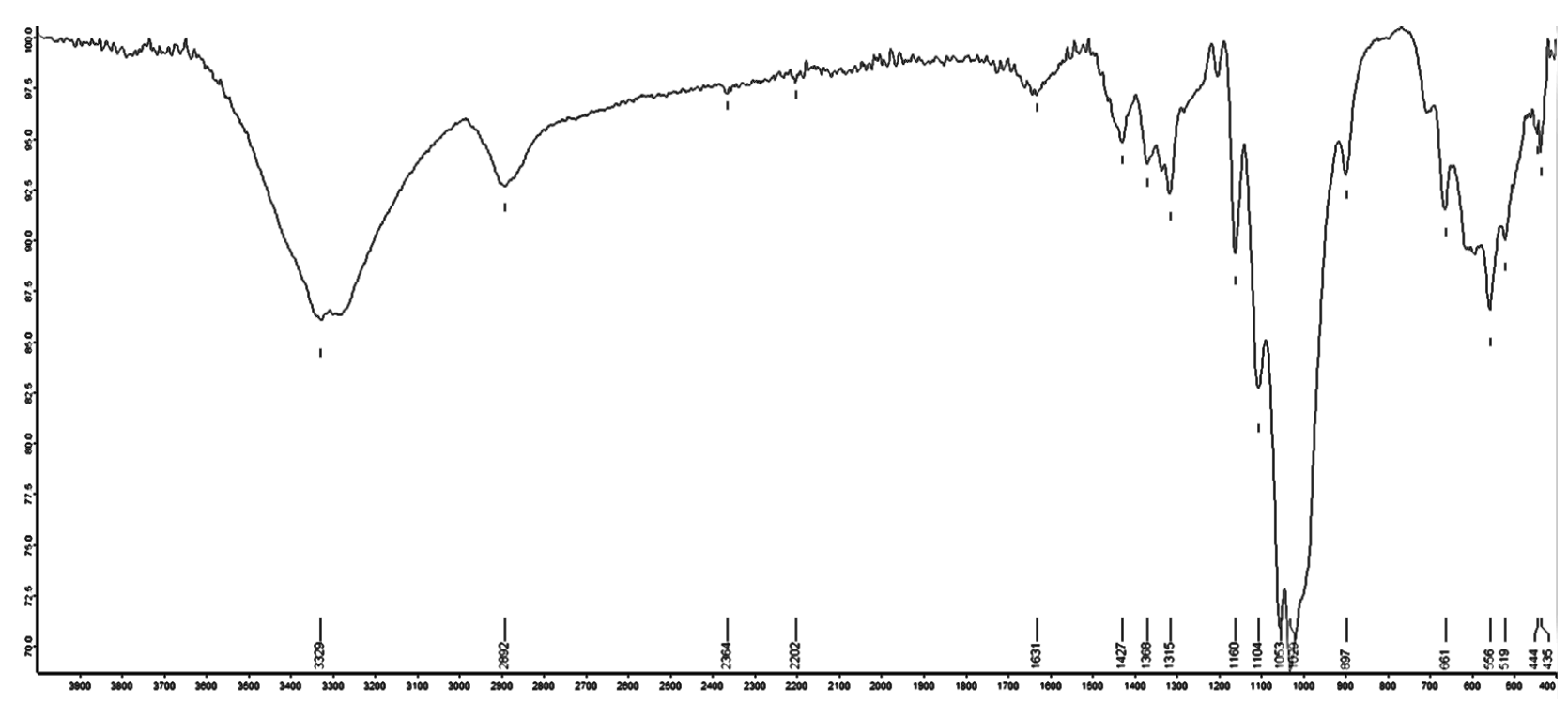

Figure 2: FT-IR spectra for MCC from papyrus reeds

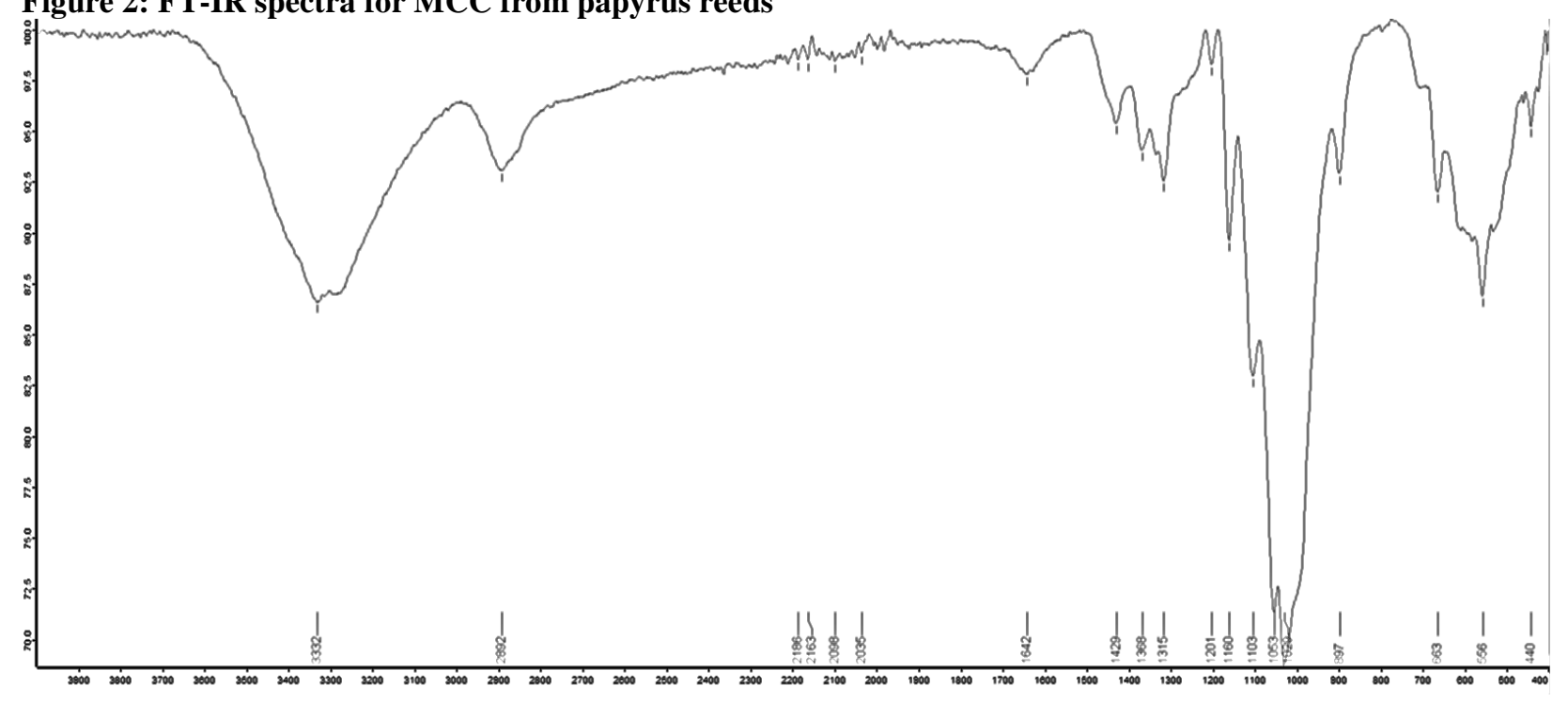

Figure 3: FT-IR spectra for MCC obtained from rice straws 


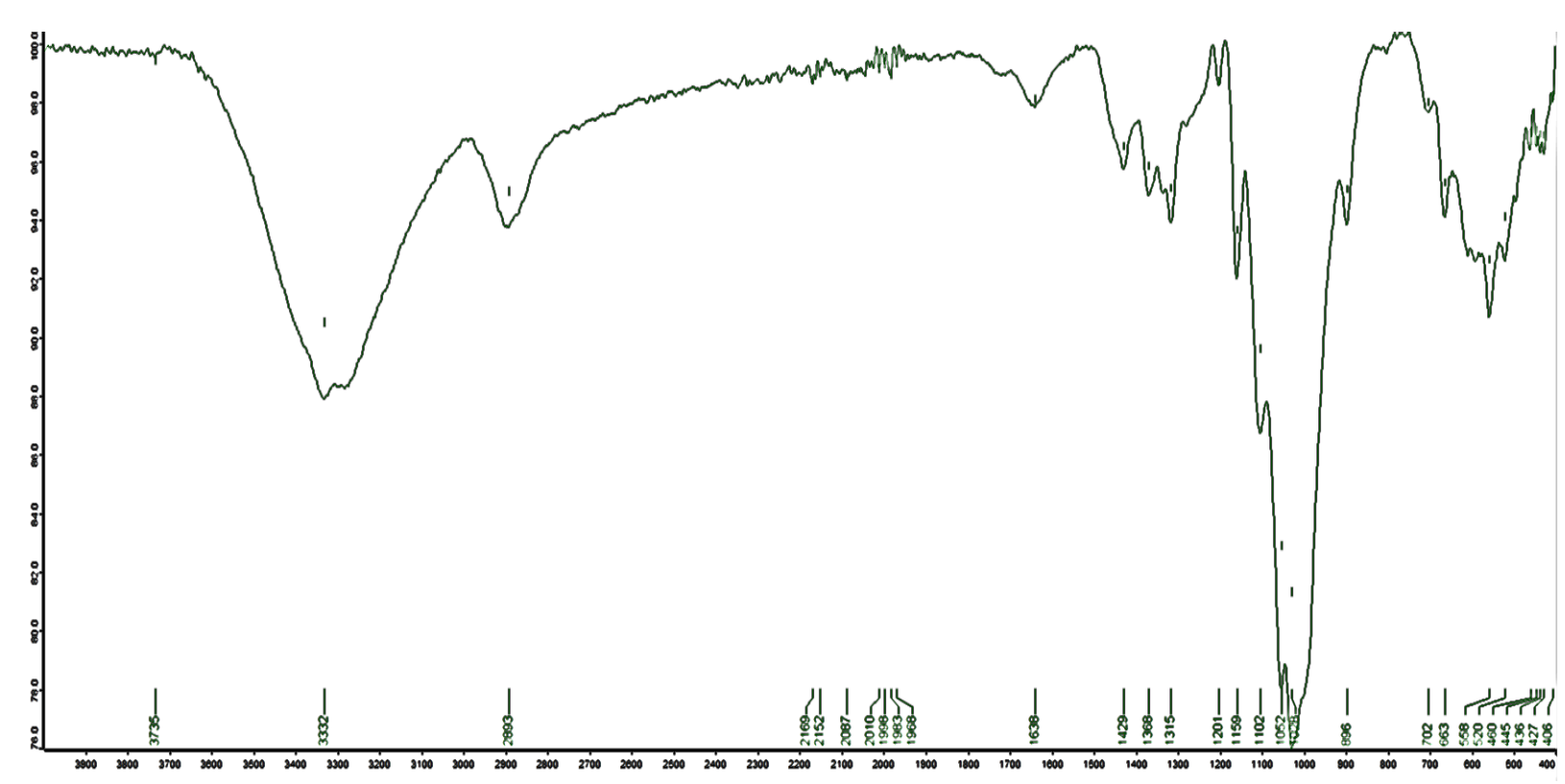

Figure 4: FT-IR spectra for MCC from banana stem

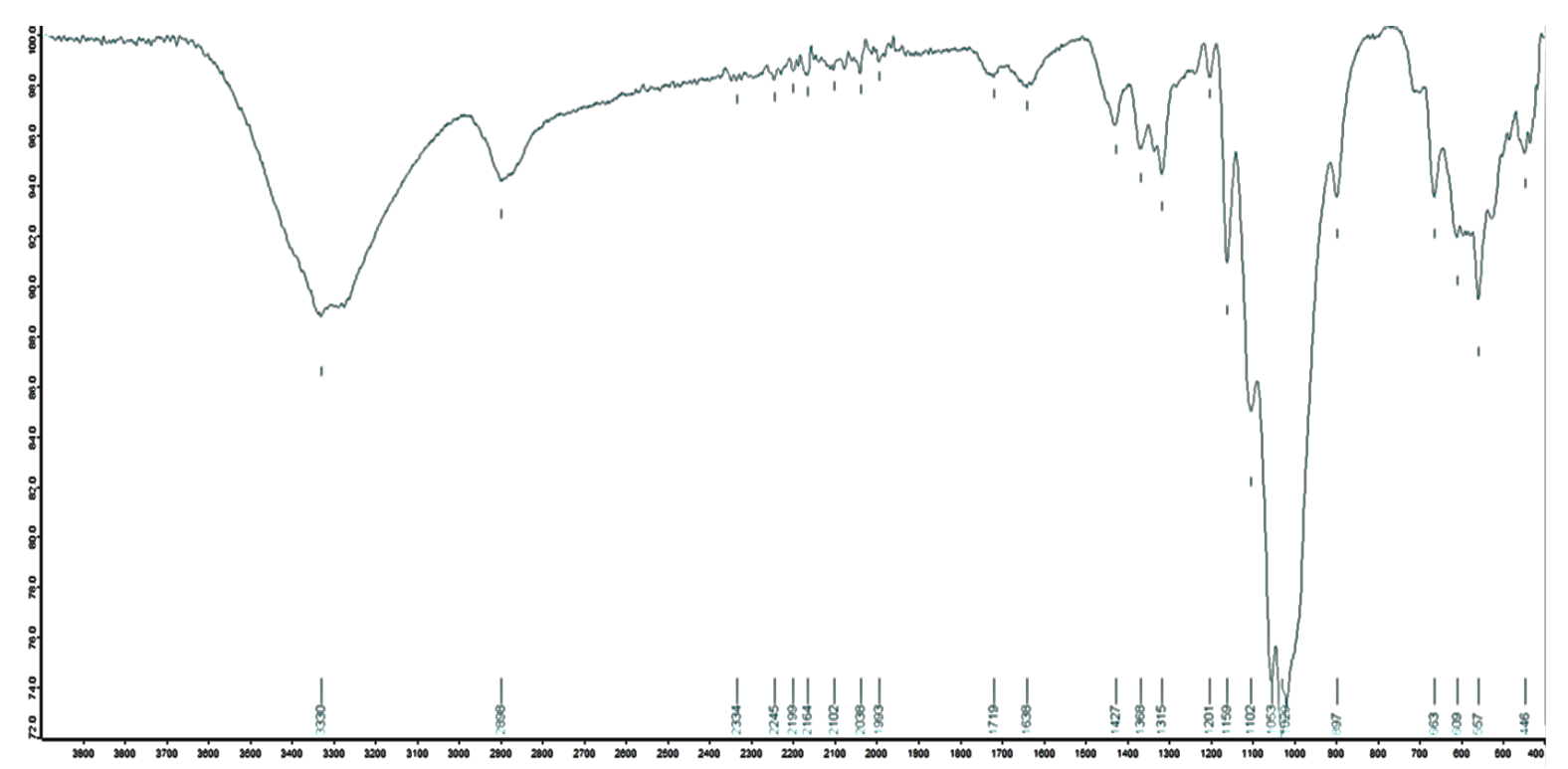

Figure 5: FT-IR spectra for citric acid modified MCC prepared from rice straws

\section{Interpretation of TGA Results}

Figures 6-8 depicted the thermal degradation for microcrystalline cellulose from various biomasses MCC from water hyacinth, papyrus reeds, rice straws and banana stem had similar degradation profiles as shown in figures 6 and 7. TGA curves showed that all samples had three degradation stages except for citric acid modified MCC (figure 8). An initial drop between $60-150{ }^{\circ} \mathrm{C}$ was noted for all samples and probably due to the presence of moisture. Several studies on the thermal decomposition of the individual components of lignocellulosic materials indicated that decomposition of hemicellulose started first, followed by the cellulose and, finally, the lignin (Chouchene et al, 2010; Dejong et al, 2003; Edmond et al, 2012; Gardner et al, 2008; Ibrahim et al, 1989).. Small amounts of residue obtained after thermal decomposition may be due to small amounts of calcium oxalate crystals of lignin and other sources of ash (Chen et al, 2011). Ash produced by cellulose consists mainly of polycyclic aromatic compounds (Gronli et al, 2002). Higher onset temperatures are associated with higher thermal stability. Thermal stability was in the order: rice straw MCC > water hyacinth MCC > papyrus reeds MCC > citric acid modified rice straw MCC > banana stem MCC, with rice straw MCC being the most stable one. Of all the samples analyzed, only citric acid modified MCC had two degradation stages that were as a result of esterification at the hydroxyl position thereby reducing the amount of water evolved during the analysis. This was also indicated by the mass loss which is higher as compared to other samples analyzed. 


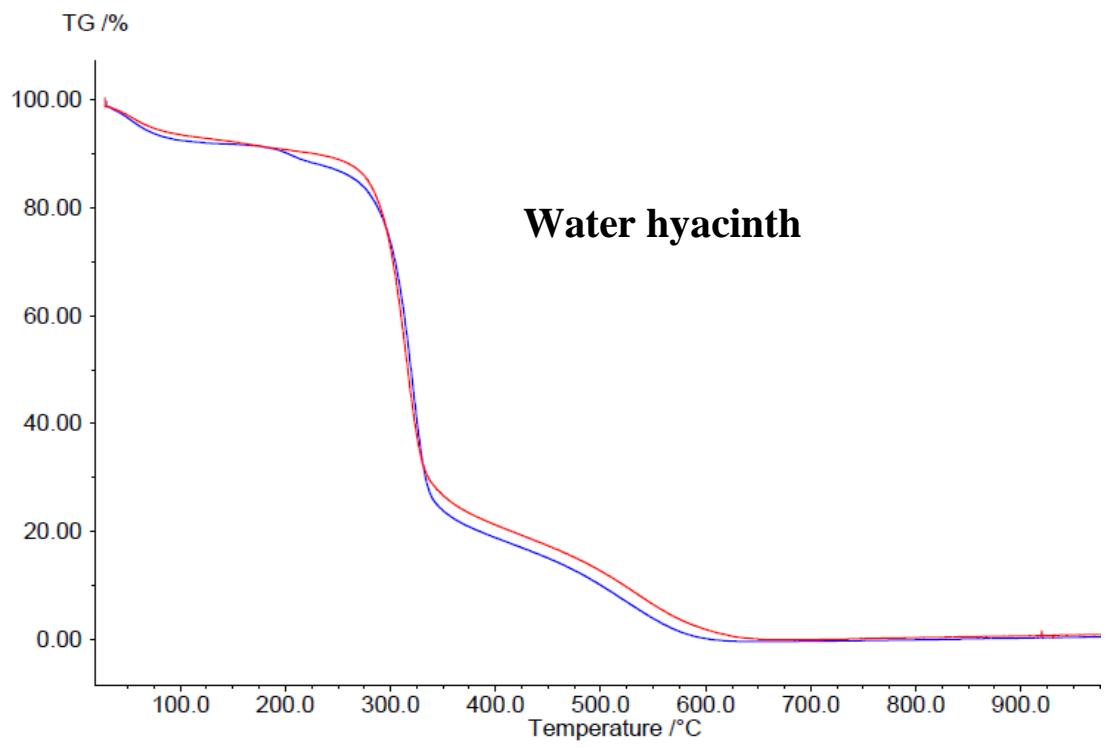

Figure 6: TGA Curves of MCC prepared from waternananan stem

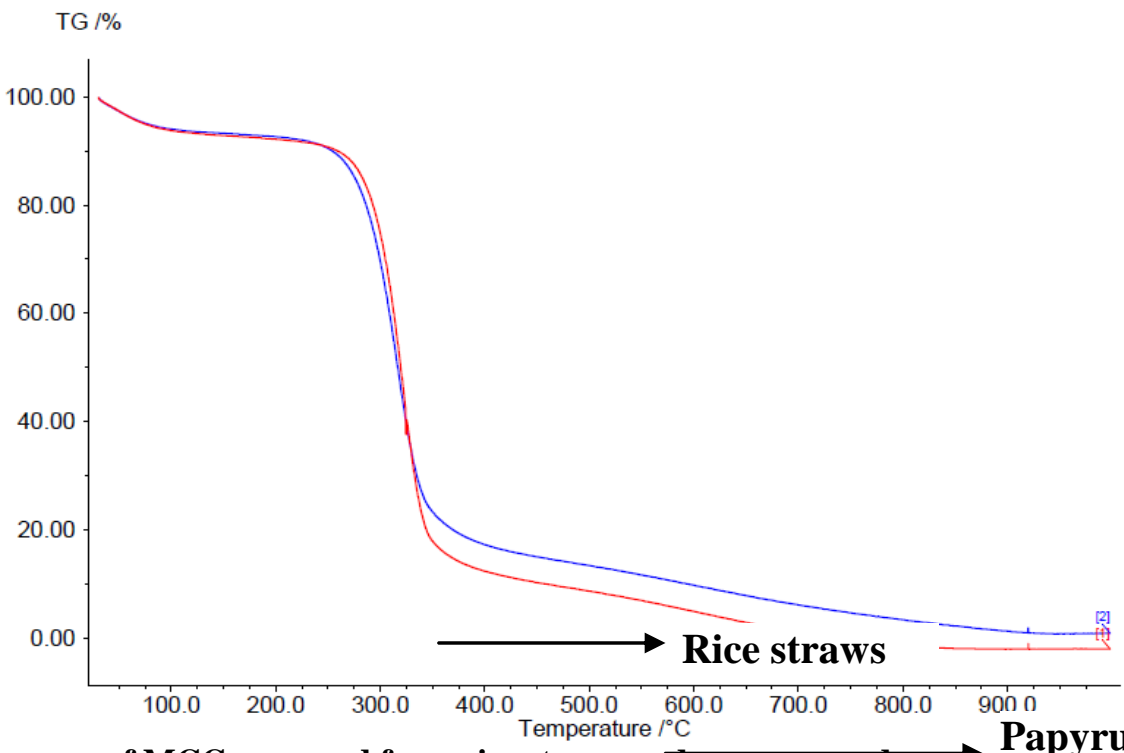

Figure 7: TGA curves of MCC prepared from rice straws and papyrus reeds $\longrightarrow$ Papyrus reeds

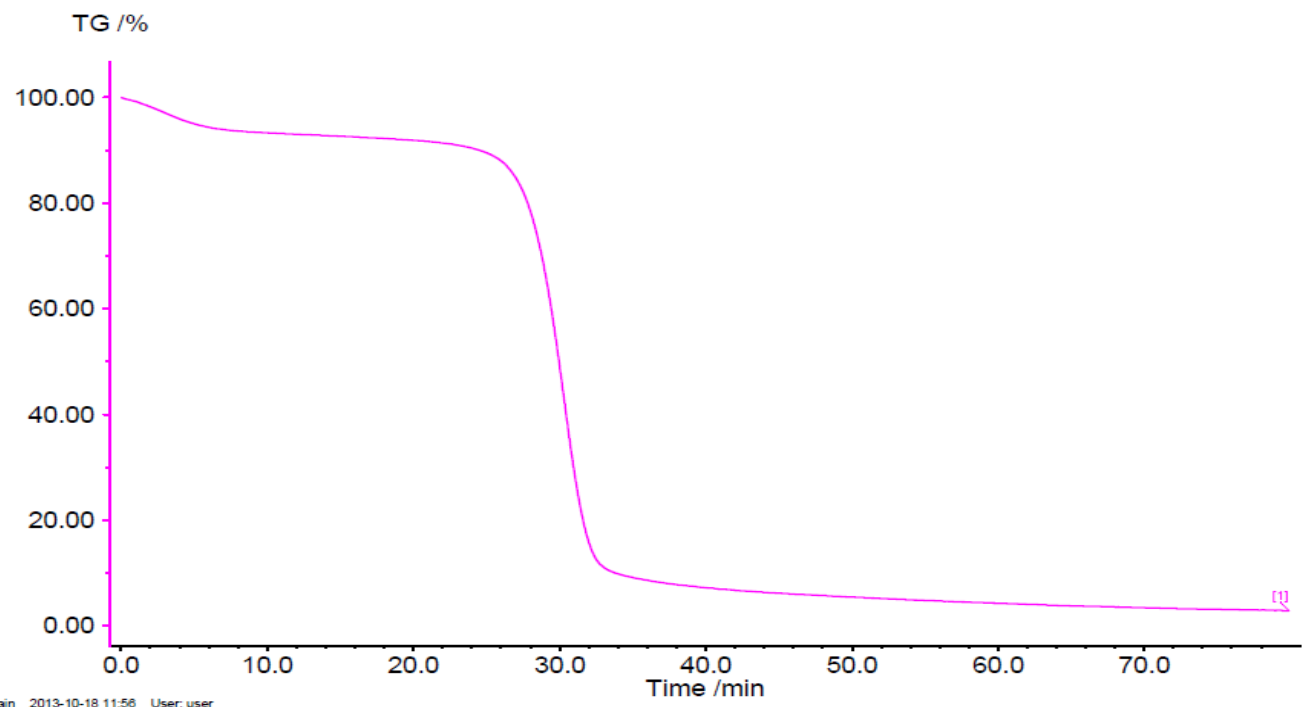

Figure 8: TGA curve of citric acid modified MCC 


\section{Interpretation of DSC Results}

Figures 9 - 13 depict the thermo-grams obtained for MCC from different lignocellulosic biomasses. A large endothermic peak at around $80{ }^{\circ} \mathrm{C}$ was noted during the first heating scan for all cellulose samples. This was associated with water loss during heating. The remaining endothermic peaks obtained corresponded to decomposition peaks (Azubuike et al, 2012). The glass transition temperatures of cellulose lie in the range of 200 to $230{ }^{\circ} \mathrm{C}$, which is close to its thermal decomposition temperature of $260^{\circ} \mathrm{C}$ (Dufresene, 2012).

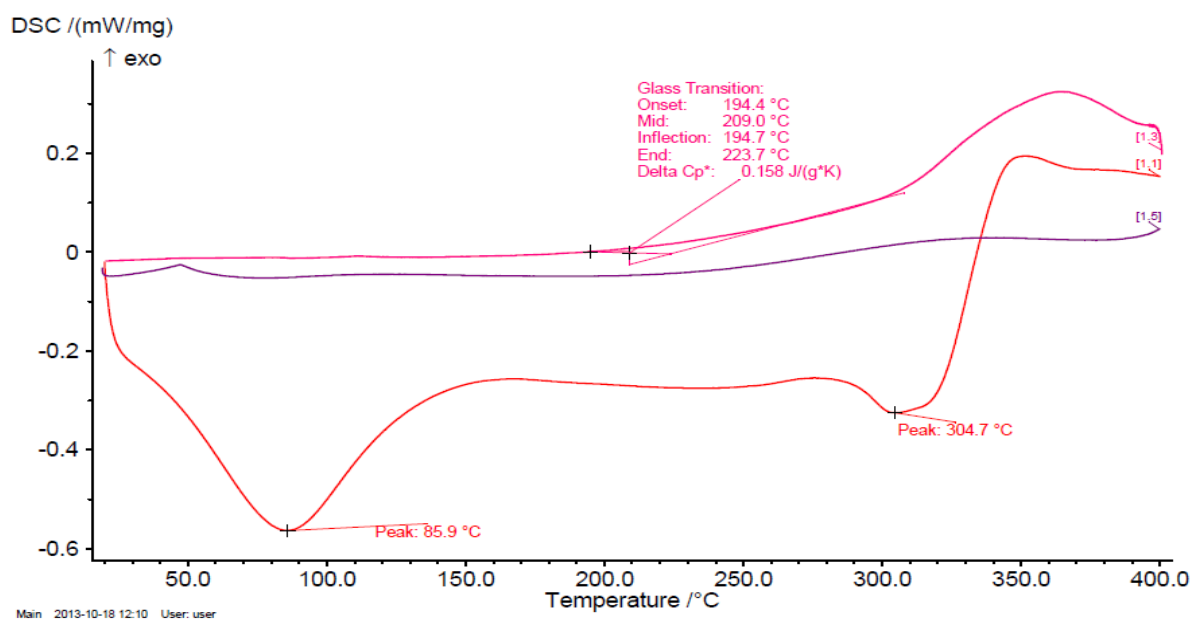

Figure 9: DSC trace of MCC prepared from water hyacinth

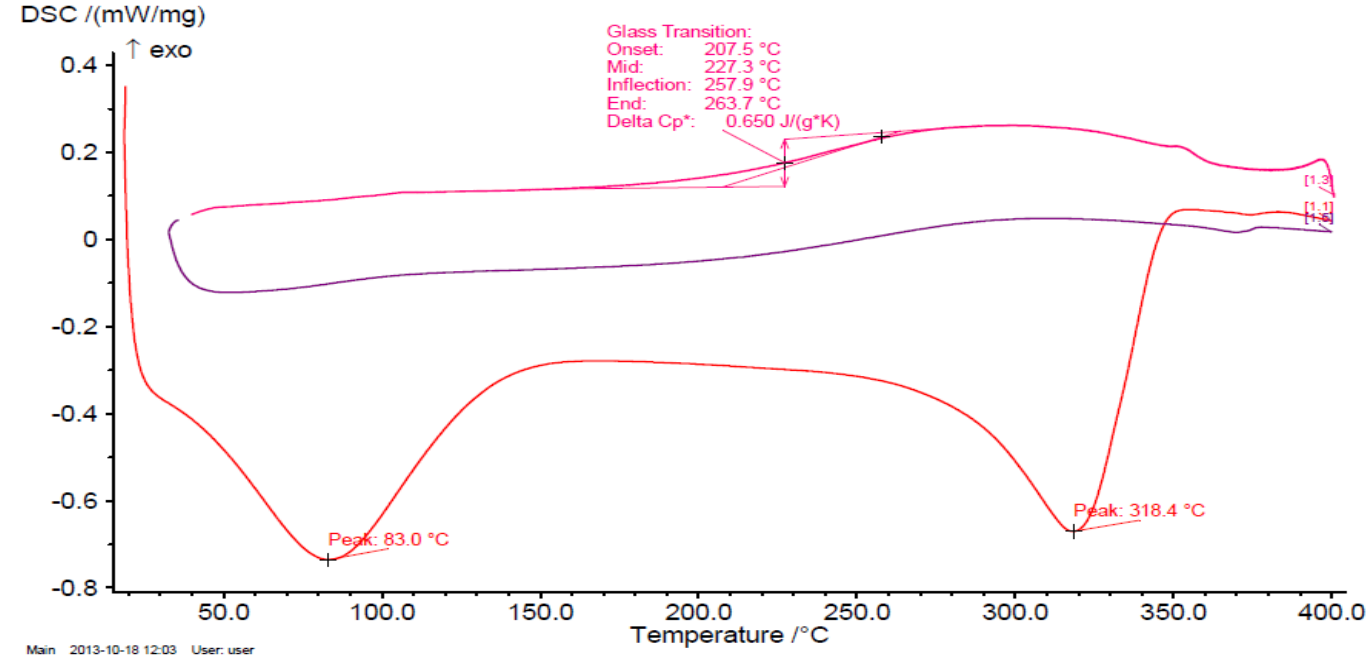

Figure 10: DSC trace of MCC prepared papyrus reeds

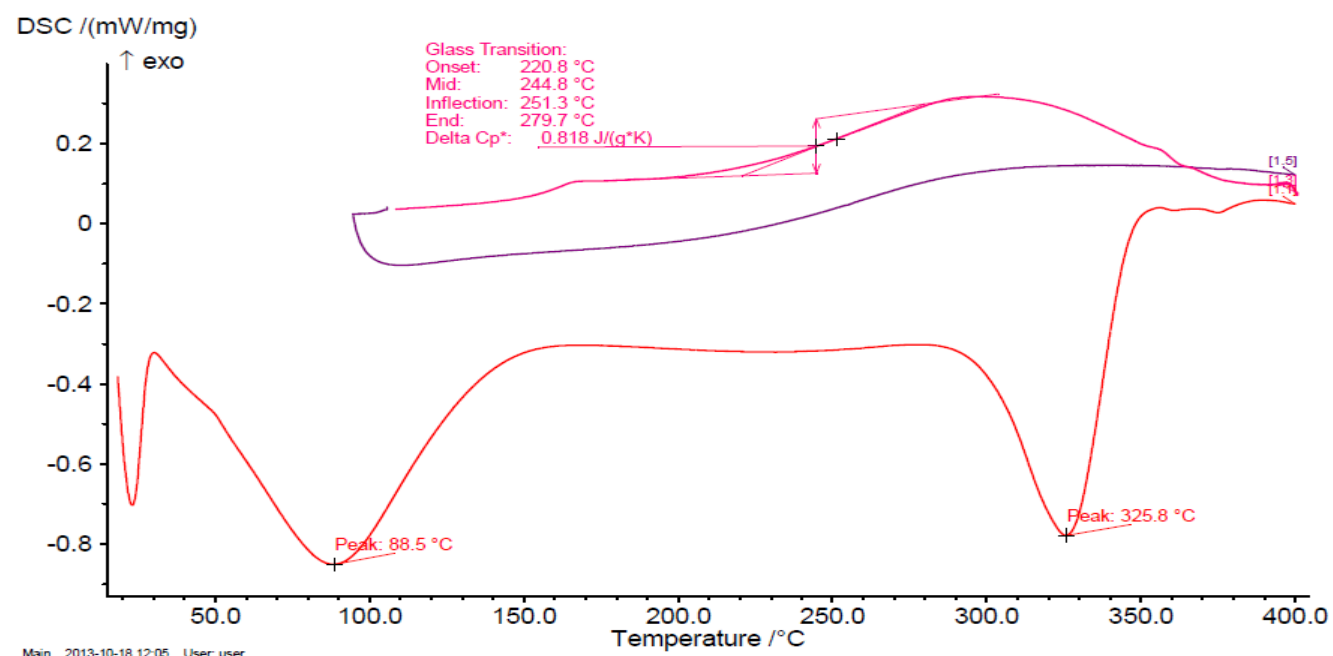

Figure 11: DSC trace of MCC prepared from rice straws 


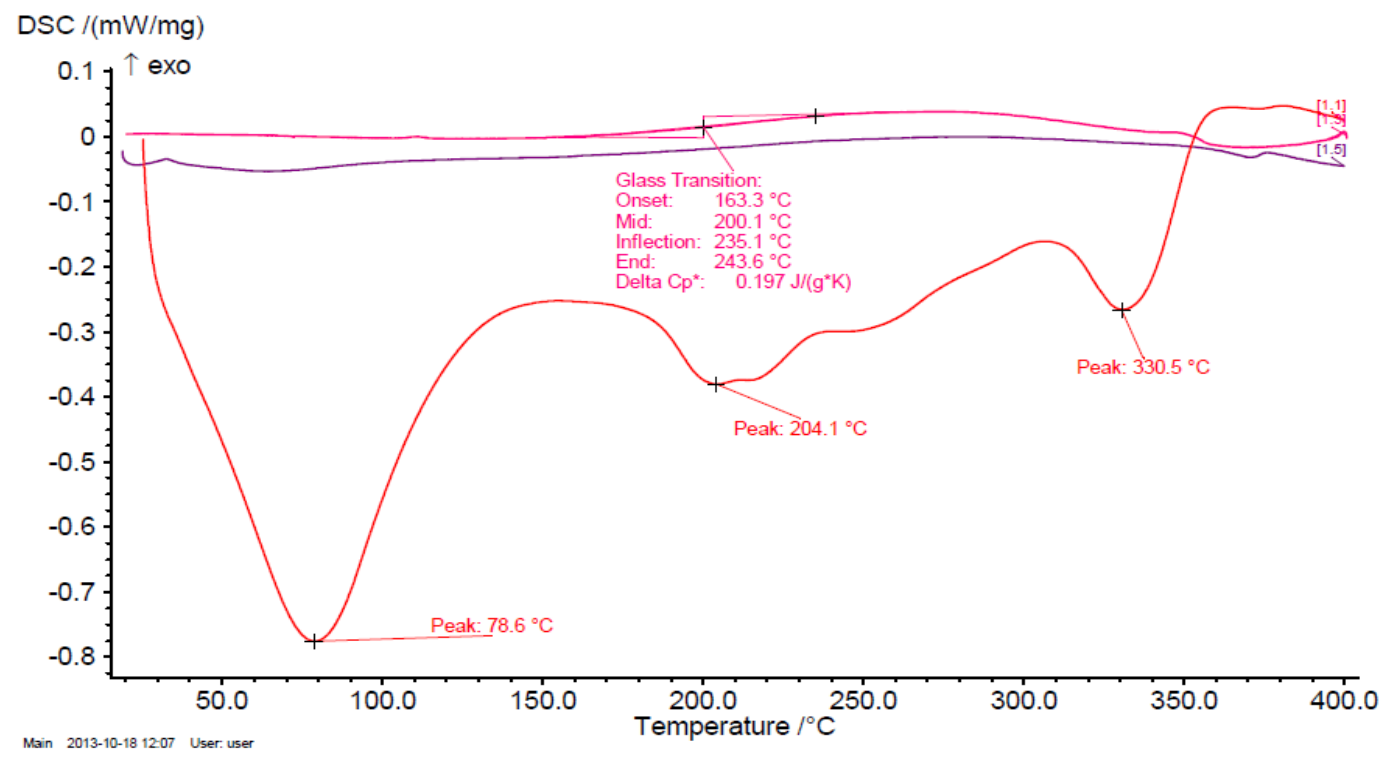

Figure 12: DSC trace of MCC prepared from banana stem

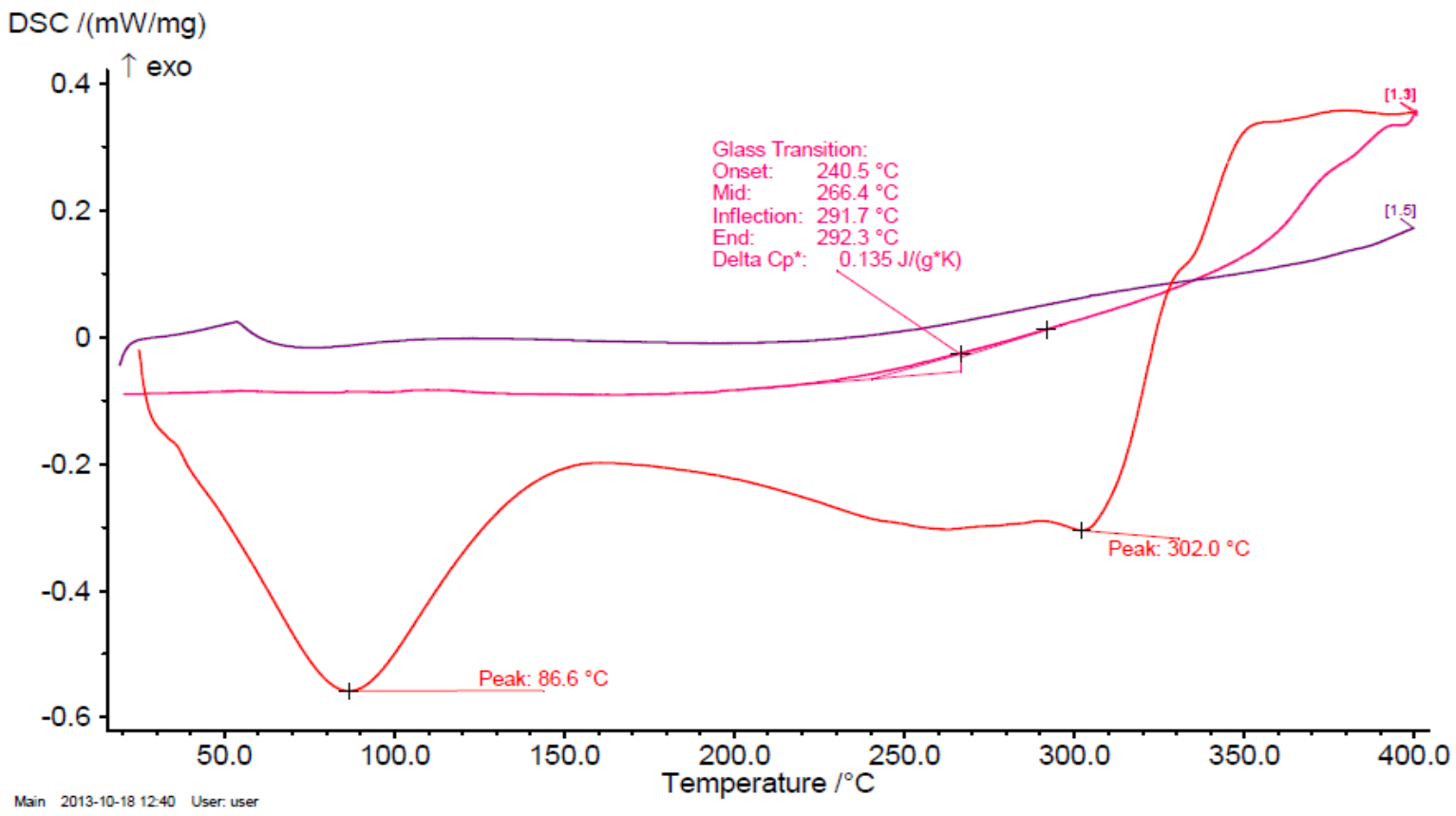

Figure 13: DSC trace of citric acid modified MCC

\section{Interpretation of SEM results}

Figures $14-17$ indicated the SEM micrograms of microcrystalline cellulose obtained from different lignocellulosic biomasses under different magnifications. Conceptually, nanocomposites refer to multiphase materials where at least one of the constituent phases has one dimension less than $100 \mathrm{~nm}$. Nanometric reinforcements can be classified according to their morphology, i.e. spherical, rod-like and platelet-like nanoparticles that present three, two and one nanometer-scale dimension, respectively (Dufresne, 2012). From the SEM results, MCC synthesized is mainly composed of rod-like and platelet-like cellulose microfibrils. The 100-300 nm magnification showed details of the fibril matrix structure while the 1-10 nm magnification showed details of the fibril. The degree of crystallinity and typical dimensions of cellulose nanofibrils were dependent on their origin (Dufresne, 2012; Janardhan et al, 2007; Luz et al, 2008) thus it was observed that the surface morphogy of the isolated cellulose microfibrils of banana and water hyacinth differed considerably at all magnifications. The effectiveness of the pretreatment process was very high, as particles and fibers whose diameters range between $300 \mathrm{~nm}-1 \mu \mathrm{m}$ were observed for the case of water hyacinth and $200 \mathrm{~nm}-3 \mu \mathrm{m}$ in banana sample. Therefore, pretreatment of banana and water hyacinth biomass materials resulted in synthesis of cellulosic fibrillar nanocomposite materials of different sizes and composition. 

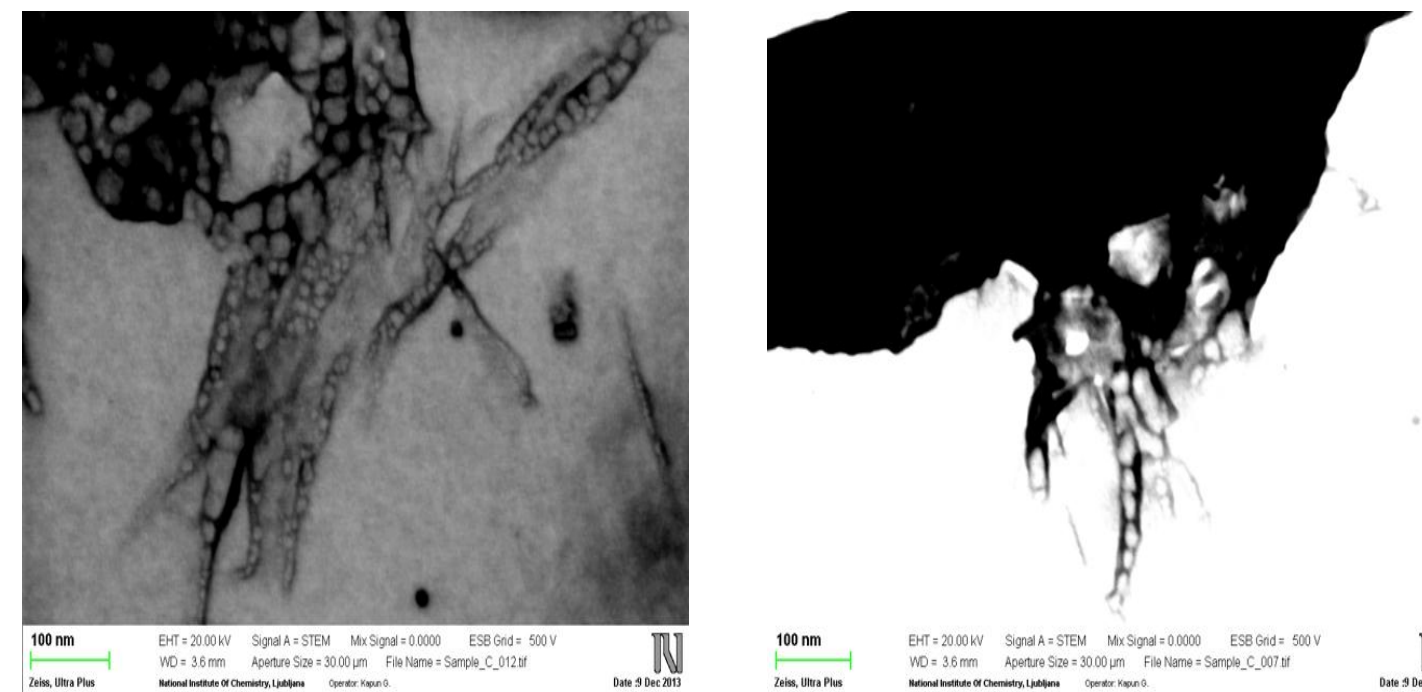

Figure 14: SEM micrograms of MCC from banana stem at different magnifications
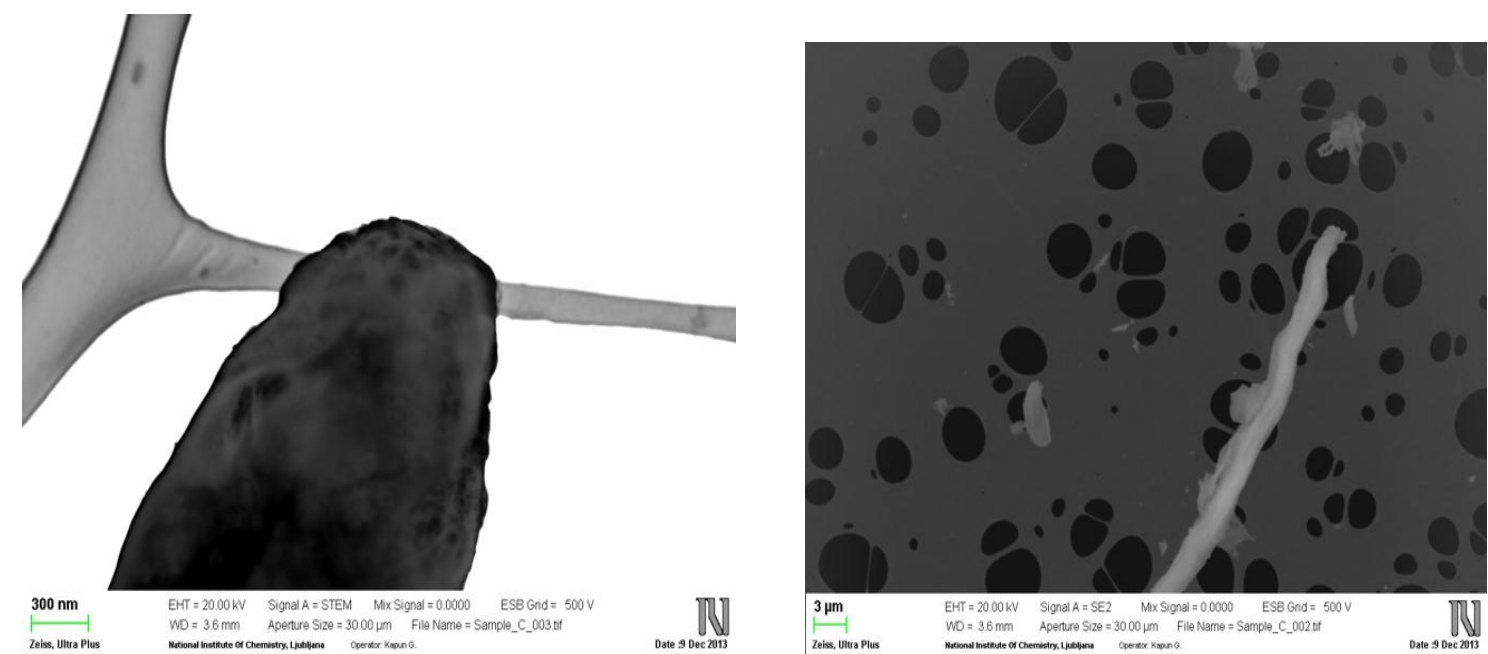

Figure 15: SEM micrograms of MCC from banana stem at different magnifications
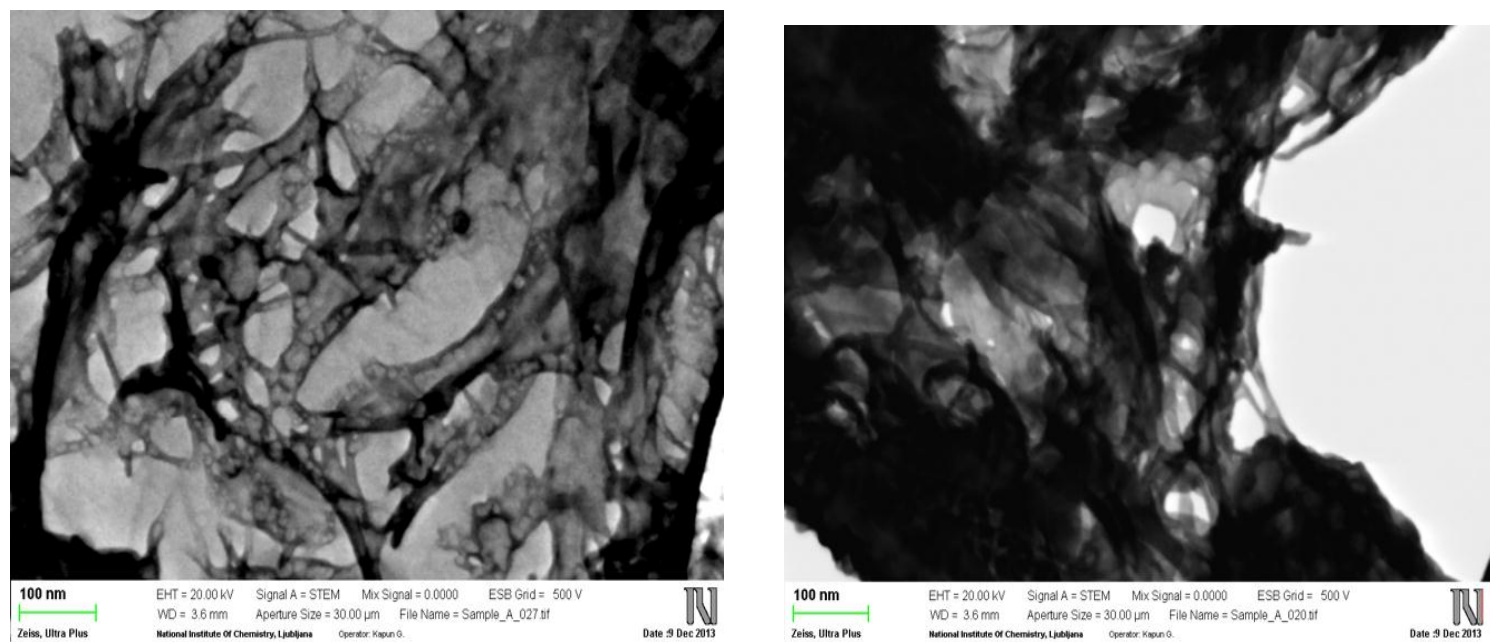

Figure 16: SEM micrograms of MCC from water hyacinth at different magnifications 

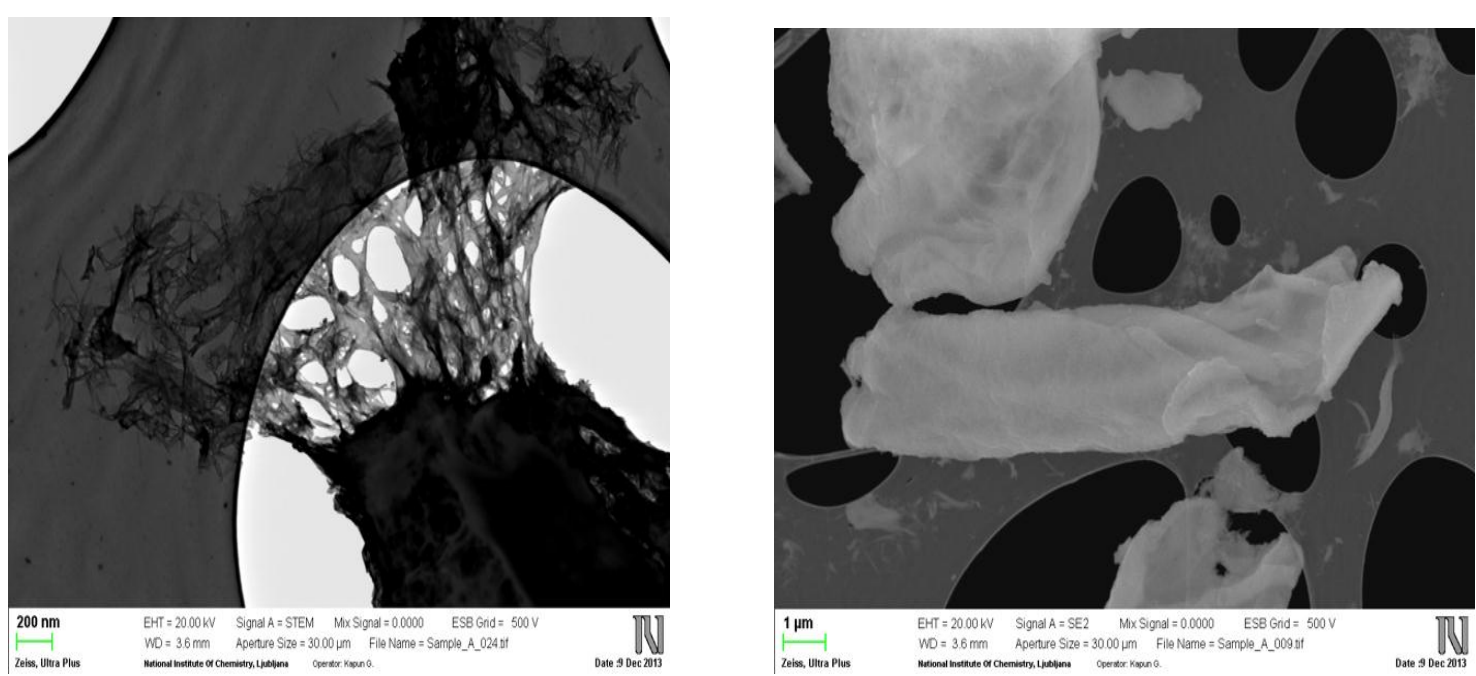

Figure 17: SEM micrograms of MCC from water hyacinth at different magnifications

\section{Conclusions}

The results obtained here indicated that microcrystalline cellulose with varying physical characteristics but similar chemical properties could be obtained from different lignocellulosic biomasses. It was observed that water hyacinth had the highest yield of microcrystalline cellulose while banana stem has the lowest yield. On the other hand, MCC obtained from water hyacinth had superior compatibility and compressibility properties while MCC synthesized from banana had better flow properties. It was also noted that MCC from papyrus reed has the highest water retention capacity as compared to those synthesized from water hyacinth, rice straws and banana stem.

Thermal gravimetric analysis of the various MCC synthesized indicated that MCC from rice straw were more thermally stable as compared to MCC from the other sources. Presence of two degradation stages and high residual mass in citric acid modified MCC was an indication of esterification that was brought about by addition of citric acid on the cellulose network thereby a reducing the number of hydroxyl groups. The size and diameters of MCC synthesized from water hyacinth were smaller as compared to that synthesized from banana stem as indicated by the SEM results.

\section{Acknowledgements}

The authors are grateful for financial support from Research Production and Extension division for financial support. Thanks to CBBR, University of Mauritius for recording TGA, DSC and FTIR data and to PoliMat of Slovenia for SEM micrograms.

\section{References}

[1]. Azubuike C. P., Esiaba J. (2012). Investigation into some physico-technical and tableting properties of low-crystallinity powdered cellulose prepared from corn residues. Journal of Pharmaceutical Research and Opinion 2: $894-98$

[2]. Azubuike C. P. and Okhamafe A. O., (2012). Physicochemical, spectroscopic and thermal properties of microcrystalline cellulose derived from corn cobs. International Journal of Recycling of Organic Waste in Agriculture 1:9.

[3]. Azubuike C. P., Oduluja O. J., and Okhafame O. A. (2012). Physicotechnical, spectroscopic and thermogravimetric properties of powdered cellulose and microcrystalline cellulose derived from groundnut shells. J. excipients and food chem 3(3) $106-114$

[4]. Chen, X., Yu, J., Zhang, Z., \& Lu, C. (2011). Study on structure and thermal stability properties of cellulose fibers from rice straw. Carbohydrate polymers, 85(1), 245-250.

[5]. Chouchene, A., Jeguirim, M., Khiari, B., Zagrouba, F., \& Trouvé, G. (2010). Thermal degradation of olive solid waste: influence of particle size and oxygen concentration. Resources, Conservation and Recycling, 54(5), 271-277.

[6]. DeJong. W., Pirone. A., Wojtowicz. M. A. (2003). Pyrolysis of Miscanthus giganteus and wood pellets: TG-FTIR analysis and reaction kinetics. Fuel 82, 1139-1147

[7]. Dufresne A. (2012). Nanocellulose: Potential reinforcement in composites. Natural polymers: Nanocomposites (2), 1 - 32, doi:10.1039/9781849735315-00001

[8]. Edmond Lam, Keith B. Male, Jonathan H. Chong, Alfred C.W. Leung, John H.T. Luong (2012). Applications of functionalized and nanoparticle-modified nanocrystalline cellulose. Trends in Biotechnology, 30: (5) 283-290

[9]. Gardner, D. J., Oporto, G. S., Mills, R., \& Samir, M. A. S. A. (2008). Adhesion and surface issues in cellulose and nanocellulose. Journal of Adhesion Science and Technology, 22(5-6), 545-567.

[10]. Ghaly and Ergudenler, (1991). Thermal degradation of cereal straws in air and nitrogen. Journal of Applied Biochemistry and Biotechnology 27, 111-126

[11]. Granstrom M. (2009). Cellulose derivatives: synthesis, properties and application. An academic dissertation submitted to faculty of science university of Helsinki, 22nd May 2009 
[12]. Grønli, M. G., Várhegyi, G., \& Di Blasi, C. (2002). Thermogravimetric analysis and devolatilization kinetics of wood. Industrial \& Engineering Chemistry Research, 41(17), 4201-4208.

[13]. Hari Gunasingham, Peter Y T Teo, Yee-Hing Lai, Swee-Geok Tan (1989). Chemically modified cellulose acetate membrane for biosensor applications. Biosensors 4(6): 349-359

[14]. Ibrahim, M. M., Agblevor, F. A., \& El-Zawawy, W. K. (2010). Isolation and characterization of cellulose and lignin from steamexploded lignocellulosic biomass. BioResources, 5(1), 397-418.

[15]. Janardhnan, S., \& Sain, M. M. (2007). Isolation of cellulose microfibrils-an enzymatic approach. Bioresources, 1(2), 176-188.

[16]. Luz, S. M., Del Tio, J., Rocha, G. J. M., \& Gonçalves, A. R. (2008). Cellulose and cellulignin from sugarcane bagasse reinforced polypropylene composites: Effect of acetylation on mechanical and thermal properties. Composites Part A: Applied Science and Manufacturing, 39(9), 1362-1369.

[17]. Woodcock C and A. Sarko A (1980). Macromolecules, 13, 1183-1187 